\title{
Congreso Internacional «1814: la Junta de Gobierno del Cuzco y el sur andino»
}

Lima, 19-21 de noviembre de 2014

\section{Víctor Álvarez Ponce}

\section{(2) OpenEdition}

Journals

Edición electrónica

URL: http://journals.openedition.org/bifea/6018

DOI: $10.4000 /$ bifea.6018

ISSN: 2076-5827

\section{Editor}

Institut Français d'Études Andines

\section{Edición impresa}

Fecha de publicación: 1 diciembre 2014

Paginación: 665-668

ISSN: 0303-7495

\section{Referencia electrónica}

Víctor Álvarez Ponce, « Congreso Internacional «1814: la Junta de Gobierno del Cuzco y el sur andino» », Bulletin de l'Institut français d'études andines [En línea], 43 (3) | 2014, Publicado el 08 diciembre 2014, consultado el 06 noviembre 2020. URL : http://journals.openedition.org/bifea/6018 ; DOI : https://doi.org/10.4000/bifea.6018

Les contenus du Bulletin de l'Institut français d'études andines sont mis à disposition selon les termes de la licence Creative Commons Attribution - Pas d'Utilisation Commerciale - Pas de Modification 4.0 International. 
CONGRESO INTERNACIONAL «1814: LA JUNTA DE GOBIERNO DEL CUZCO Y EL SUR ANDINO»

Lima, 19-21 de noviembre de 2014

La Pontificia Universidad Católica del Perú (PUCP) y el Instituto Francés de Estudios Andinos en Lima (IFEA)-Servicio Científico de la Embajada de Francia en el Perú, organizaron el congreso internacional titulado: «1814: la junta de 
CONGRESO INTERNACIONAL

1814 : La Junta de Gobierno del Cuzco y el Sur Andino

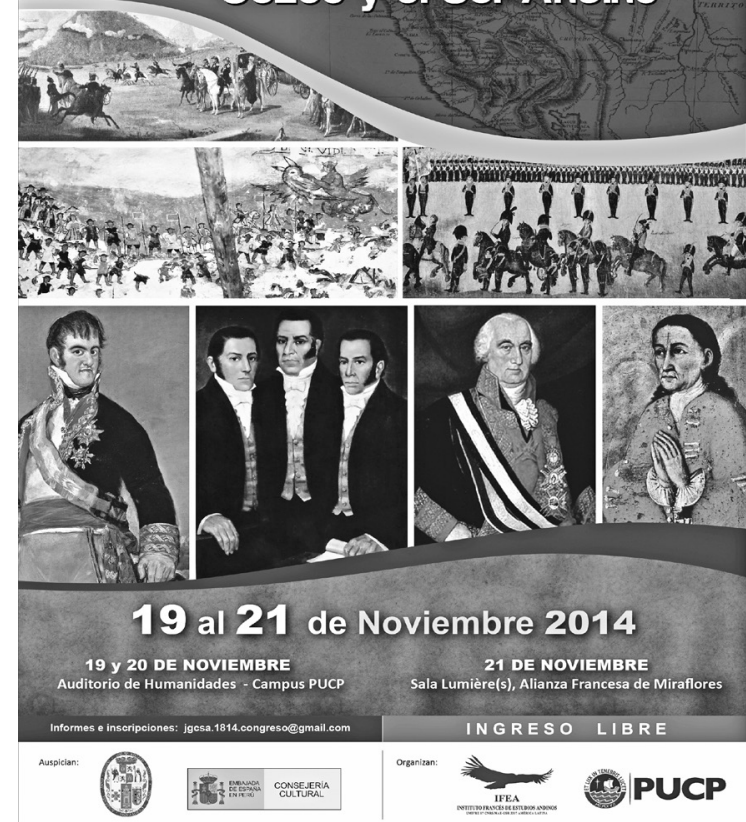

gobierno del Cuzco y el sur andino». Este congreso se llevó a cabo los días 19, 20 y 21 de noviembre de 2014 en la ciudad de Lima y contó con la participación de 21 investigadores, 11 de los cuales fueron invitados exclusivos, provenientes de diversas universidades de América y Europa.

El inicio de las jornadas contó con la presencia del rector de la PUCP, el Dr. Marcial Rubio, quien inauguró este importante evento internacional. Le acompañaron en la mesa de honor el director de la Maestría de Historia de la Escuela de Posgrado PUCP, el Dr. Jesús Cosamalón; el director del IFEA, el Dr. Gérard Borras; y la coordinadora general del congreso, la Dra. Scarlett O'Phelan. Cabe destacar que, a nivel diplomático, estuvieron presentes en dicha inauguración el Agregado Cultural de la Embajada de España, el Sr. Francisco de Asis Barrera López; y el Embajador de Bolivia en el Perú, el Dr. Gustavo Rodríguez Ostria.

La charla Inaugural estuvo a cargo del Dr. John Fisher de la Universidad de Liverpool, en el Reino Unido, reconocido historiador internacional que no había estado en el Perú desde hacía 14 años. Su ponencia fue titulada La Pepa viaja al Pacífico: el impacto del liberalismo peninsular en el virreinato del Perú, 1809-1814.

El programa del congreso contempló la organización de nueve mesas temáticas y una relatoría. Durante la primera jornada, celebrada el 19 de noviembre, la Mesa 1, titulada «Constitucionalismos», estuvo conformada por el Dr. Brian Hamnett, de la Universidad de Essex (Reino Unido) y el Dr. Jorge Polo y la Borda, junto con la Lic. Margareth Najarro Espinoza, ambos de la Universidad San Antonio Abad del Cuzco. La Mesa 2, titulada «Cuzco 1814», contó con las presentaciones de la Dra. Núria Sala i Vila de la Universidad de Girona (España) y del Dr. David T. Garrett del Reed College, en EE.UU. Finalmente, la Mesa 3, «De Túpac Amaru a Pumacahua» y la Mesa 4, «Conceptos y discursos en el contexto de la junta cuzqueña»s se fusionaron para dar paso a las presentaciones de la Mg. Luz Peralta, de la Universidad Nacional Mayor de San Marcos y del Lic. Rolando Iberico Ruiz, de la Pontificia Universidad Católica del Perú.

La segunda jornada, celebrada el 20 de noviembre, dio inicio con la Mesa 5, titulada «Cuzco y Huamanga: sus conexiones en 1814», donde participaron el Dr. Luis Miguel Glave, de la Universidad Pablo de Olavide, en España; junto con el Mg. Nelson E. Pereyra Chávez y el Mg. Claudio Rojas Porras, ambos de la Universidad 


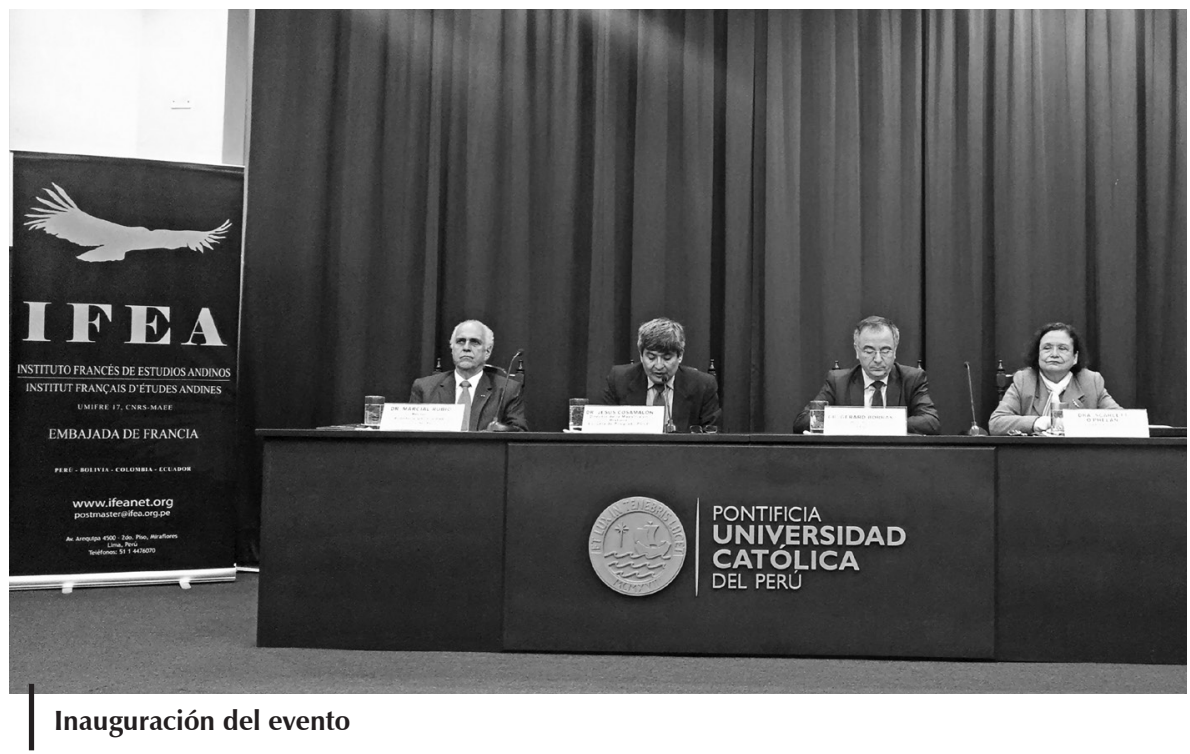

San Cristóbal de Huamanga. La Mesa 6, «La Campaña del Alto Perú», contó con las presentaciones de la Mg. Virginia Macchi, de la Universidad de Buenos Aires, en Argentina y de Dra. María Luisa Soux, de la Universidad Mayor de San Andrés, en Bolivia. Finalmente, la Mesa 7, titulada «Impacto en otros espacios del virreinato peruano», estuvo conformada por el Lic. Paul Rizo Patrón, de la Pontificia Universidad Católica del Perú, por la Dra. Elizabeth Hernández García, de la Universidad de Piura y por el Mg. Paulo Lanas Castillo, de la Universidad de Tarapacá, en Chile.

Asimismo, durante la segunda jornada se hizo un espacio especial para la presentación del libro Voces Americanas en las Cortes de Cádiz: 1810-1814, editado por la Dra. Scarlett O'Phelan y por el Dr. Georges Lomné, resultado del congreso internacional que llevó el mismo nombre, organizado por la PUCP y el IFEA en el año 2012. Los comentarios del libro estuvieron a cargo del Dr. Cristóbal Aljovín, de la Pontificia Universidad Católica del Perú y del Dr. Lizardo Seiner, de la Universidad de Lima. Acompañaron la mesa de honor, el director del IFEA, el Dr. Gérard Borras y la directora del Fondo Editorial PUCP, la Dra. Patricia Arévalo. La última jornada se celebró el 21 de noviembre en la Sala Lumière(s) de la Alianza Francesa de Miraflores. En dicha sede se presentó la Mesa 8, titulada «Impacto en otros virreinatos y capitanías generales», y dialogaron en ella el Dr. Juan Luis Ossa Santa Cruz, de la Universidad Adolfo Ibáñez, en Chile, el Mg. Daniel Morán, de la Universidad de Buenos Aires, en Argentina y el Dr. Daniel Gutiérrez Ardila, de la Universidad del Externado, en Colombia. Del mismo modo, la Mesa 9, titulada «Huánuco 1812 y Cuzco 1814» expuso las ponencias de la Dra. Joëlle Chassin, de la Universidad de Paris III (Francia) y de la Dra. Scarlett O'Phelan, de la Pontificia Universidad Católica del Perú. Finalmente, se dio paso a la relatoría 
final del congreso a cargo del Dr. Carlos Espinosa, de la Facultad Latinoamericana de Ciencias Sociales (Flacso) en Ecuador.

Cabe precisar que durante los días que se realizaron las sesiones en la PUCP, se contó con la participación de profesores del Departamento de Humanidades de la universidad, entre los que figuraron los doctores Karen Spalding, Cristóbal Aljovín, Carlos Contreras, Nicanor Domínguez y Pedro Guibovich. También se contó con la presencia de la profesora Carlota Casalino, con un nutrido grupo de estudiantes de la UNMSM. A su vez, en los momentos de mayor aforo se con la participación de hasta 85 personas en el auditorio PUCP y 60 personas en la Sala Lumière(s) de la Alianza Francesa de Miraflores. Ello, sumado a la meticulosa organización logística del congreso, ha generado las felicitaciones del caso por parte de los destacados ponentes peruanos y extranjeros que participaron en las jornadas. 